\title{
Comportamiento de la infección experimental por aislamientos colombianos de Giardia duodenalis en el modelo animal del gerbo (Meriones unguiculatus)
}

\author{
Adriana Arévalo, Sofía Duque, Rubén Santiago Nicholls \\ Grupo de Parasitología, Instituto Nacional de Salud, Bogotá, D. C., Colombia.
}

Introducción. Se han informado infecciones naturales y experimentales con Giardia sp. en bovinos, equinos, caprinos, caninos, felinos y roedores como ratones, ratas y gerbos; estos últimos son el modelo más adecuado para estudios de la infección por Giardia duodenalis y Giardia muris.

Objetivo. Establecer el comportamiento de la infección con aislamientos colombianos de Giardia duodenalis en el modelo animal del gerbo.

Materiales y métodos. Se purificaron mediante gradientes de sacarosa y percoll quistes del parásito obtenidos a partir de heces de pacientes sintomáticos infectados. La inoculación a los animales se realizó mediante sonda gástrica con $5 \times 10^{3}$ quistes. El curso de la infección se estableció mediante recuento diario de quistes y semanal de trofozoítos durante treinta días. Resultados. La eliminación de quistes presentó un patrón intermitente de excreción, con ausencia en la primera y cuarta semanas de infección, y presencia constante durante la segunda y tercera semanas, en número variable con promedio mínimo de 79 y máximo de 17.943 quistes liberados en heces recolectadas en un período de dos horas. Se observó colonización de los trofozoítos en el intestino delgado, en número que osciló entre 15.000 y 6'577.778 trofozoítos por ml.

Conclusiones. En gerbos infectados con aislamientos de Giardia duodenalis circulantes en otras regiones geográficas, la resolución natural de la infección oscila entre 86 y 114 días mientras que los gerbos infectados con aislamientos colombianos del parásito la resuelven al día 30. El gerbo constituye un modelo animal adecuado para la infección con aislamientos colombianos de G. duodenalis. La infección experimental por Giardia en gerbo permite obtener quistes y trofozoítos del parásito en cantidades suficientes con la finalidad de ser utilizados como antígenos para la inmunización de animales y para la obtención de anticuerpos que puedan utilizarse para la detección de antígeno de Giardia en materia fecal.

Palabras clave: Giardia, gerbo, Meriones unguiculatus, infección, quiste, trofozoíto.

Experimental infection of the gerbil (Meriones unguiculatus) by Colombian isolates of Giardia duodenalis

Introduction. Natural and experimental Giardia infections have been reported from bovines, equines, goats, canines, felines and rodents such as mice, rats and gerbils. The latter have provided successful animal models for Giardia duodenalis and Giardia muris experimental infections.

Objective. The gerbil model was used to establish the pattern of infection of Colombian Giardia human isolates.

Materials and methods. Giardia cysts were obtained from stool specimens of symptomatic giardiasis patients by means of sucrose-percoll gradients. Animal inoculation was performed by gastric intubation and injection with $5 \times 10^{3}$ Giardia cysts. The course of infection was established by counting cysts every day and trophozoites weekly throughout a period of 30 days.

Results. The pattern of cyst excretion was found to be intermittent. Cysts were released during the second and third weeks of infection but not during the first or fourth weeks. The mean 
minimal number of cysts released per 2-hr collection period was 79 and the mean maximum number was 17,943 . Colonization of the small intestine by trophozoites was observed with a mean number ranging from 15,000 to $6,577,778$ trophozoites $/ \mathrm{ml}$.

Discussion and conclusions. Gerbils inoculated with $G$. duodenalis isolates obtained from geographical areas outside Colombia resolved the infection between 86 and 114 days after infection, whereas gerbils infected with Colombian $G$. duodenalis isolates resolved the infection at 30 days. The gerbil proved to be a good animal model for experimental infection with Colombian isolates of $G$. duodenalis. Experimental Giardia infection of gerbils permit a sufficient yield of cysts and trophozoites to be used as antigens for the immunization of other animals and to obtain Giardia antibodies that could be used for Giardia antigen detection assays in stool specimens.

Keywords: Giardia, gerbil, Meriones unguiculatus, infection, cyst, trophozoite.

La giardiosis es la infección intestinal humana causada por el protozoario flagelado Giardia lamblia, también conocido como G. intestinalis o G. duodenalis (1). Otras especies de Giardia ocasionan parasitismo en mamíferos, aves, anfibios y reptiles (2).

Giardia es uno de los patógenos más comunes que causa infección intestinal a nivel mundial (3) y cuya prevalencia varía según la población estudiada (4). En la población colombiana, según la primera encuesta nacional de morbilidad, 1965-1966, la prevalencia fue del 11,9\% (5) y en la segunda, 1977-1980, del 13,4\% (6). Los estudios realizados en 1995 en niños colombianos de 12 a 59 meses de edad demostraron prevalencias del $21,2 \%$ (7) y en niños de 3 a 13 años alojados en asentamientos temporales posterremoto en Armenia fue del 65\% (Torres E., Gallego M.L., Gómez J.E. Giardiasis en niños viviendo en asentamientos temporales en Armenia. III Encuentro Nacional de Investigación en Enfermedades infecciosas, Popayán, Colombia. Infectio 2002.p.89).

La giardiosis se asocia con la ingestión de agua o alimentos contaminados por heces humanas que contienen quistes del parásito, agua mal filtrada o con tratamiento inadecuado (8). Otras fuentes de infección adicionales al hombre incluyen los castores (9), quizá, las ratas almizcleras y,

\footnotetext{
Correspondencia:

Adriana Arévalo, Avenida Calle 26 No. 51-60, Bogotá, D.C., Colombia

Teléfono: (571) 220 7700, extensión 455; fax: (571) 220

7700 , extensión 457

aarevalo@ins.gov.co

Recibido: 20/01/05; aceptado: 25/04/05
}

posiblemente, algunos animales domésticos (10) y silvestres (11). Se ha comprobado que algunos animales como perros, gatos, castores y rumiantes pueden encontrarse naturalmente infectados 0 pueden ser infectados experimentalmente con especies de Giardia y, posiblemente, dar origen a la infección en humanos, en cuyo caso esta parasitosis podría considerarse como una zoonosis (12). Los humanos son los hospederos principales de G. duodenalis (13). Sin embargo, se ha observado que animales domésticos, perros y gatos (13), o de granja como terneros, corderos, lechones y potros son hospederos importantes de Giardia (14).

Durante los últimos cuarenta años se han estudiado infecciones naturales y experimentales por Giardia en una gran variedad de animales como ratas, ratones, gatos, perros y gerbos, y estos últimos son el modelo animal más adecuado para estudiar las infecciones con $G$. duodenalis y $G$. muris (15).

La posibilidad de que las ratas fuesen susceptibles a infección con aislamientos humanos de Giardia fue explorada por primera vez por Hegner en 1927 (16) y Armaghan en 1937 (17); encontraron que tan sólo 4 de 45 de ellas se infectaron; la infección tuvo una duración de 15 días y no se observó formación de quistes. Goritskaya y Vrublevskaya en 1966 (18) inocularon ratas lactantes con aislamientos humanos del parásito y observaron que 58 de 85 de ellas se infectaron. Sehgal et al. en 1976 (19) inocularon ratas adultas y lactantes con 1,9 a $3,3 \times 10^{3}$ quistes de aislamientos humanos de Giardia pero tan sólo 5 de 31 ratas adultas y 7 de 19 lactantes se infectaron. Woo y Paterson en 1987 (20) no lograron infectar ratas 
Wistar adultas con G. duodenalis. Los resultados de los estudios anteriores sugieren que las ratas no son modelos útiles para los estudios de giardiosis por su baja susceptibilidad a la infección.

Los ratones han sido utilizados para estudiar la biología, la inmunología, la patología y el tratamiento de la giardiosis. Sin embargo, infecciones exitosas con G. duodenalis ocurren sólo en ratones lactantes y jóvenes, edad en el que su sistema inmune es inmaduro. Por lo tanto, los resultados obtenidos con estos ejemplares son difíciles de interpretar y su utilidad como modelos animales para estudios de giardiosis podría ser cuestionada (15). Vinayak et al., en 1979 (21), lograron infectar con $1,5 \times 10^{5}$ quistes el $100 \%$ de ratones suizos lactantes pero Hill et al., en 1983 (22), observaron que la susceptibilidad de los ratones a la infección con inóculos de Giardia es dependiente de la edad de éstos. Boreham et al., en 1986 (23), inocularon con $10^{5}$ trofozoítos de Giardia ratones lactantes e informaron que éstos pueden utilizarse para estudios quimio-terapéuticos. Ratones suizos albinos de 2-3 semanas de edad inoculados con $1 \times 10^{4}$ quistes se han utilizado para estudios de inmunidad celular, humoral y adquirida (24-26). Samra et al., en 1987 (27), observaron baja absorción de glucosa, fenil-alanina, lisina y ácido aspártico al inocular ratones suizos con $1 \times 10^{4} \mathrm{y}$ $1 \times 10^{5}$ quistes de Giardia.

Kirkpatrick y Greene en 1985 (28) informaron que los gatos adultos no son muy susceptibles a la infección al igual que lo informado por Woo y Paterson (20) con gatos jóvenes.

Hewlett et al., en 1982 (29), al inocular perros con trofozoítos del parásito observaron una susceptibilidad a la infección del $37 \%$ y no se conocen evidencias documentadas de transmisión al humano de Giardia de perros infectados (30).

Faubert y Belosevic en 1990 (15) estudiaron al gerbo como modelo animal para estudios de giardiosis utilizando $G$. duodenalis dadas las diferencias fisiológicas existentes entre especies de Giardia y aislamientos humanos del parásito de diferentes áreas geográficas.

Con el auge de la biología y la medicina, los modelos animales se han utilizado con la finalidad de conocer aspectos relacionados con la infección que eventualmente puedan extrapolarse a humanos. Los estudios de aislamientos de $G$. duodenalis de diferentes hospederos sugieren que la variación intraespecífica ocurre dentro del grupo (13) y el humano es el principal reservorio del parásito. Faubert y Belosevic (15), utilizando al gerbo como modelo animal para estudios de giardiosis, observaron que el patrón de excreción de quistes varía entre diferentes aislamientos humanos y Nash et al., en 1988 (31), demostraron la acentuada variabilidad antigénica en la superficie de trofozoítos del parásito.

Se han demostrado grandes diferencias entre diferentes aislamientos de $G$. duodenalis con respecto a proteínas de superficie (32), perfiles antigénicos (33), patrones por enzimas de restricción (34) y patrones isoenzimáticos (35). Los estudios in vitro han revelado que un sólo trofozoíto de distintos aislamientos puede generar organismos con diferentes antígenos de superficie $(31,36)$ e igual fenómeno se ha observado al estudiar la infección in vivo en gerbos con aislamientos de Giardia de humanos (37). La infección experimental en gerbos ha permitido, entre otros estudios, comparar la antigenicidad de diferentes aislamientos y la relación entre los perfiles antigénicos y la patogenicidad de clones (cepa WB) del trofozoíto de G. lamblia. Nash et al., en 1990 (38), demostraron que la variación antigénica de Giardia en infecciones humanas y la respuesta humoral del hospedero son en parte aislamiento-específicas. Es posible que debido a la variabilidad genética del parásito, los patrones de excreción de quistes de Giardia sean característicos por áreas geográficas y que la respuesta a sus antígenos sea también específica.

Por lo tanto, este estudio se propuso establecer el curso de la infección por quistes de aislamientos colombianos de $G$. duodenalis, de origen humano, en el modelo animal del gerbo.

\section{Materiales y métodos \\ Muestras de materia fecal}

Se recolectaron muestras de materia fecal de 35 pacientes con giardiosis clínicamente sintomática que habían consultado a los laboratorios clínicos 
del Hospital Infantil Lorencita Villegas de Santos (HILVS) y al Centro de Salud No.78 José María Carbonell de Bosa, ambos localizados en Bogotá, D. C.

\section{Diagnóstico parasitológico de G. duodenalis}

Se realizó la identificación del parásito mediante examen directo en solución salina fisiológica y coloración con lugol (39) y por concentración con formol (Merck 4003)-éter (Merck 921) $(39,40)$. Se examinó al microscopio en 100X y 400X.

\section{Preservación de quistes del parásito}

Se diluyeron las heces completamente con agua destilada, se filtraron a través de gasa (41) y se almacenó el filtrado a $4^{\circ} \mathrm{C}(42)$.

\section{Obtención de quistes de G. duodenalis}

Se purificaron quistes de Giardia a partir de heces humanas mediante gradientes de sacarosa (Sigma S9378) y percoll (Sigma P1644). Se homogenizaron $5 \mathrm{ml}$ del filtrado de materia fecal almacenado a $4^{\circ} \mathrm{C}$ y se completó a un volumen de $14 \mathrm{ml}$ con agua destilada. Después, se lavó el filtrado mediante centrifugación a $400 \mathrm{~g}$ durante 5 minutos a $18^{\circ} \mathrm{C}$ y se resuspendió el sedimento con agua destilada. A 1 volumen de sacarosa $1 \mathrm{M}$, densidad 1,11 g/ml, se adicionó 1 volumen de la suspensión obtenida y se centrifugó a $400 \mathrm{~g}$ durante 5 minutos a $18^{\circ} \mathrm{C}$. Luego, se removieron los quistes de Giardia concentrados en la interfase agua-sacarosa, se verificó su presencia mediante observación microscópica, se lavaron con agua destilada centrifugando a $400 \mathrm{~g}$ durante 5 minutos a $18^{\circ} \mathrm{C}$, se resuspendieron en agua destilada y se realizó el recuento de quistes del parásito bajo observación microscópica en laminilla de $22 \times 22 \mathrm{~mm}$ (43). Posteriormente, se vertió 1 volumen de la suspensión sobre 1 volumen de $40 \%$ de Percoll y se centrifugó a $400 \mathrm{~g}$ durante 5 minutos a $18-20^{\circ} \mathrm{C}$ lavando dos veces consecutivas el precipitado (quistes de Giardia). Finalmente, se resuspendieron los quistes en 1 $\mathrm{ml}$ de agua destilada y se guardó la suspensión a $4^{\circ} \mathrm{C}$ hasta el momento de ser utilizada $(44,45)$.

\section{Infección experimental en gerbos}

Se utilizó el gerbo/Agouti, Meriones ungüiculatus, cepa:Agouti, línea: Cenp MON, categoría genética: no consanguíneo, categoría microbiológica: mínima contención (M-CON), suministrado por el bioterio del Instituto Nacional de Salud (INS), sexo: machos, edad: 6-10 semanas.

Se siguieron los parámetros de temperatura, humedad y ventilación establecidos internacionalmente para la cría y mantenimiento de animales en bioterio. Para su alimentación se les suministró Rodentina $^{\circledR}$, concentrado especialmente preparado por Purina ${ }^{\circledR}$ para roedores, y agua en un bebedero que se cambiaba tres veces por semana. El suministro de alimento y agua era ad libitum. Desde el momento de su admisión al bioterio de experimentación, los animales se sometieron a cuarentena y readaptación durante 5-15 días, tiempo recomendado para gerbos, observando la desaparición de todos los riesgos (tensión o estrés, angustia, trastornos de salud) antes de considerarlos adaptados de acuerdo con el concepto del médico veterinario $(46,47)$.

Se les suministró, a los gerbos, metronidazol (Flagyl $\left.{ }^{\circ} 250\right) 20$ mg/gerbo por día, por vía oral, durante tres días consecutivos, como medida de profilaxis y se realizó el diagnóstico parasitológico seriado de tal manera que sólo se utilizaron gerbos que se encontraban libres de parásitos intestinales.

Se infectaron experimentalmente 56 gerbos con un inóculo de $5 \times 10^{3}$ quistes de Giardia en un volumen de $0,2 \mathrm{ml}$ de solución salina fisiológica. La infección se hizo mediante intubación con sonda nasogástrica impregnada con lidocaína. Como controles se utilizaron 4 gerbos inoculados con $0,2 \mathrm{ml}$ de solución salina fisiológica.

\section{Estudio de la infección experimental}

Se realizó el estudio del curso de la infección mediante la observación microscópica de quistes y trofozoítos de Giardia y la cuantificación de éstos (48).

Se recolectó la materia fecal a cada uno de los gerbos diariamente durante 30 días consecutivos para establecer el patrón de liberación de quistes de los aislamientos colombianos de Giardia. Se disolvieron $0,5 \mathrm{~g}$ de heces en $5 \mathrm{ml}$ de solución salina reguladora de fosfatos (PBS) $0,1 \mathrm{M}, \mathrm{pH}$ 7,2 , y se hizo el diagnóstico parasitológico a cada muestra. Se obtuvieron quistes de Giardia según 
la metodología descrita anteriormente para purificación de quistes de Giardia a partir de heces humanas y se efectuó el recuento de quistes liberados.

Se suministró sólo agua a los gerbos desde el día anterior a su sacrificio para estudiar la colonización de trofozoítos de Giardia en el intestino delgado. Se les practicó individualmente eutanasia a 12 gerbos dentro de cámara de $\mathrm{CO}_{2}$ según la metodología de Hughes (49) y se repitió a los días 1, 7, 14, 21, 28 y 30 . Se realizó disección del peritoneo, se localizó el intestino delgado, el cual se resecó, se cortó longitudinalmente, se rasparon sus paredes con una hoja estéril de bisturí y el producto obtenido del raspado, el cual contenía los trofozoítos de Giardia, se suspendió en $13 \mathrm{ml}$ de PBS. Finalmente, se realizó recuento de los trofozoítos liberados en una alícuota de $20 \mathrm{ml}$ que se observó bajo el microscopio de luz con aumento de 400X.

Todos los procedimientos anteriormente señalados fueron avalados por el Comité de Ética del Instituto Nacional de Salud, de acuerdo con lo establecido en la Resolución No. 008430 del Ministerio de Salud.

\section{Cuantificación de quistes y trofozoítos de G. duodenalis}

La cuantificación de quistes y trofozoítos del parásito se realizó, de manera independiente, utilizando un hemocitómetro (48) y como medida de tendencia central se estimó la media ( 0 promedio) (50).

\section{Resultados}

Se observó un patrón intermitente de excreción de quistes del parásito con ausencia de éstos en la primera y cuarta semanas de la infección y con presencia constante de quistes de G. duodenalis durante la segunda y tercera semanas posinfección (figura 1). Durante este período, el promedio de la concentración de quistes del parásito varió dentro del rango de $79\left(\log _{10}: 1,9\right)$ a $7.943\left(\log _{10}: 3,9\right)$ quistes liberados durante dos horas de recolección de heces (figura 1). El patrón de excreción de quistes no ocurrió en forma progresiva, en el cual el número inferior debería corresponder al primer día de excreción del

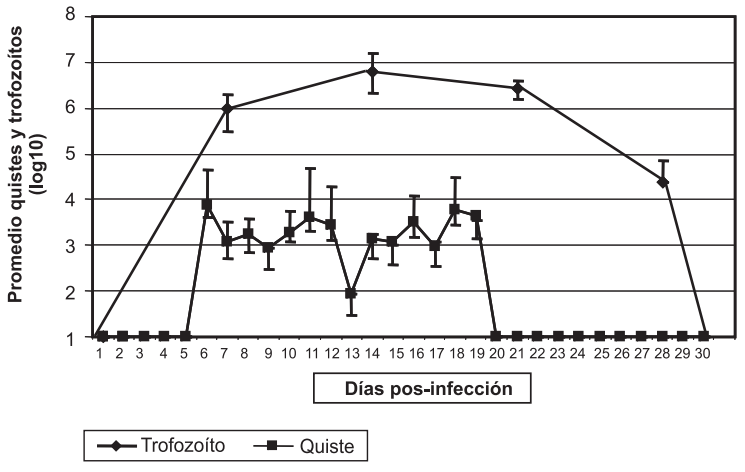

Figura 1. Patrón de excreción de quistes y trofozoítos de Giardia durante la infección experimental en gerbos (Meriones unguiculatus).

parásito y el número mayor al último día de excreción de quistes de Giardia, sino que los quistes fueron excretados en cantidades diferentes cada día. Así, en el gerbo No.3 (figura 2) en el día 7 se observaron quistes y en los días siguientes, 8 a 10, no se observaron para luego ser visualizados en los días 11, 12 y 13, y nuevamente en los días 18 a 20, día después del cual ya no se observó excreción de formas parasitarias.

Debido a la gran diferencia en los órdenes de magnitud entre el número de quistes y el de trofozoítos obtenidos en la recolección, y para poder visualizar gráficamente su comportamiento de liberación, se recurrió a la transformación logarítmica de los datos (figura 1). El número de trofozoítos de $G$. duodenalis recuperados del

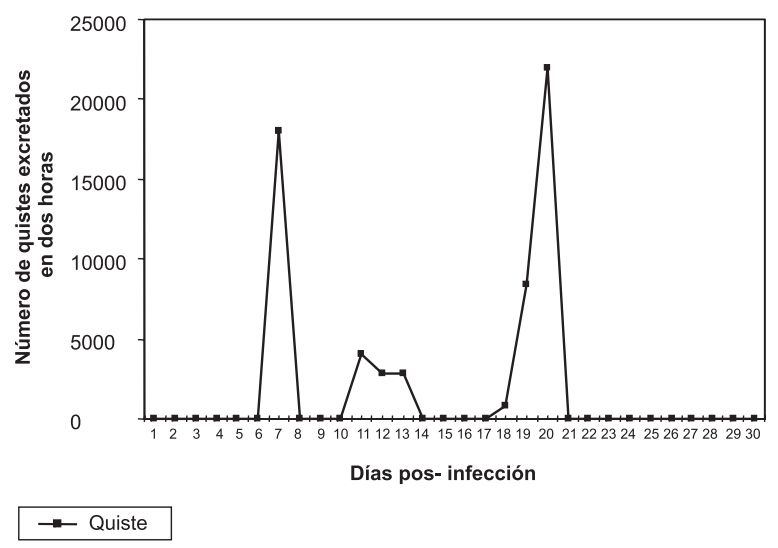

Figura 2. Excreción de quistes en la infección experimental por Giardia en el gerbo No.3. 
intestino delgado fue diferente en cada una de las observaciones realizadas con un rango entre $15.000\left(\log _{10}: 4,2\right)$ y 6'577.778 $\left(\log _{10}: 6,8\right)$ trofozoítos/ml y la colonización del parásito en el intestino delgado fue progresiva durante la segunda y tercera semanas posinoculación (figura 1).

\section{Discusión}

Los patrones del curso de infección por Giardia en diferentes especies animales demuestran una excreción intermitente de quistes característica del parásito según el animal infectado. En terneros, la mayor eliminación de quistes se observa entre la primera y sexta semana posinfección (14) y este patrón es semejante en ovejas (51), potros y caballos (14). En gatos ha sido más difícil establecer el patrón de excreción de quistes por la dificultad en obtener el coprológico seriado de estos animales (52). En perros infectados con aislamientos de $G$. duodenalis, se ha observado que la excreción cíclica de quistes del parásito ocurre con mayor intensidad entre la segunda y tercera semanas posinfección (29), igual al patrón de excreción de quistes observado en los gerbos de este estudio. Podría pensarse en utilizar a los bovinos, los caprinos, los equinos y los caninos como posibles modelos animales para estudios de giardiosis, pero son costosos y su mantenimiento en el laboratorio en términos de vivienda, nutrición y cuidado demanda mayores recursos económicos que los utilizados para un roedor como el gerbo.

Los ratones lactantes (22), recién destetados (53) y adultos (54) han sido estudiados como posibles modelos animales para estudios de giardiosis. Sin embargo, es importante considerar que los ratones lactantes y recién destetados no tienen un sistema inmune maduro como sí lo poseen los adultos. Estos últimos, se han utilizado como modelos para estudiar la relación hospedero-parásito, incluida la variabilidad genética de Giardia (55) pero se ha demostrado que los patrones de infección difieren entre las cepas de ratones utilizadas y que las respuestas inmunológicas son características de cada patrón de infección (54).

Las ratas presentan una excreción de quistes de Giardia de forma variable eliminando quistes constantemente en algunos ejemplares, otras en forma intermitente y, en algunos casos, no existe excreción de quistes del parásito (42). Las ratas no son muy útiles para estudios de giardiosis debido a su pobre susceptibilidad a la infección y a la ausencia de patología a nivel intestinal (15).

Los gerbos utilizados en el estudio permitieron establecer el comportamiento de la infección experimental con aislamientos colombianos de Giardia provenientes de pacientes sintomáticos infectados y cumplieron con los requisitos establecidos internacionalmente para ser un modelo animal para estudios de giardiosis (15): 1) los gerbos no fueron costosos (US \$2), se aparearon, se mantuvieron en las condiciones de bioterio y fueron fáciles de manejar en el laboratorio; 2) se conocía su biología, lo que garantizó el conocimiento del curso de la infección con el parásito y su aplicabilidad en estudios posteriores; 3 ) los animales se pudieron trabajar en el laboratorio según la ética y normas internacionales preservando su integridad en el momento de la infección experimental; 4) se inocularon oralmente con quistes de Giardia obtenidos de materia fecal de pacientes colombianos con giardiosis, semejando la transmisión fecal-oral como ocurre naturalmente en el medio ambiente; 5) los gerbos fueron sensibles a la infección con los aislamientos colombianos de Giardia y esto se demostró a lo largo del estudio por la presencia de quistes y trofozoítos del parásito en los ejemplares; 6 ) los trofozoítos colonizaron y se multiplicaron en el intestino delgado entre la segunda y tercera semanas de la infección permitiendo que éstos fuesen recolectados, mantenidos in vitro e iniciar un banco de aislamientos colombianos de Giardia; 7) se formaron quistes del parásito que fueron liberados en las heces intermitentemente entre la segunda y tercera semanas posinfección y esta excreción intermitente de quistes de Giardia es similar a lo que se observa en humanos.

El patrón de excreción de quistes del parásito en heces de los gerbos estudiados presenta diferencias con respecto a lo informado por Faubert y Belosevic (15) quienes inicialmente utilizaron el mismo inóculo de $5 \times 10^{3}$ quistes del parásito obtenidos de materias fecales humanas de 
Etiopía, España, Canadá, Cuba y Haití. La eliminación de quistes de Giardia en heces de gerbos inoculados con cada uno de los aislamientos del parásito obtenidos de estos países, así como con los de Colombia, se inicia en todos los ejemplares en la primera semana posinfección. La excreción intermitente de quistes del parásito se inicia antes del día sexto con los aislamientos de Etiopía, Canadá y España y a partir de éste con los aislamientos de Giardia de Haití, Cuba y Colombia (15). La excreción irregular de quistes de Giardia se observa hasta los días $20,26,51,65$ y 93 con los aislamientos del parásito procedentes de Colombia, Haití, Etiopía y Canadá, España y Cuba, respectivamente (15). Esto confirma lo informado por Faubert y Belosevic (15) acerca de que el patrón de excreción de quistes gerbos infectados con aislamientos de Giardia de diferentes regiones geográficas es una característica intrínseca del parásito e independiente de su hospedero, lo cual explica el comportamiento heterogéneo entre los diferentes aislamientos del parásito.

El patrón del curso de la infección, desarrollado por los aislamientos colombianos de Giardia en los gerbos estudiados, se caracterizó por excreción intermitente con alternación de presencia y ausencia de quistes del parásito en las heces de los ejemplares, comportamiento similar al de otros aislamientos del parásito circulantes en otros países (15). El patrón de excreción intermitente de quistes del parásito de los gerbos estudiados fue diferente al de gerbos infectados con aislamientos del parásito circulantes en Etiopía, Canadá, España, Haití y Cuba (15), tomando como criterios los días en que hubo ausencia de quistes en las heces y el número de días que esta ausencia perduró. Los aislamientos de Giardia de Etiopía y Haití presentaron una sola vez ausencia de quistes; los de Canadá y España, 3 veces; los de Cuba, 4 veces (15), y los de Colombia ninguno pero sí una baja excreción de quistes representada por 79 de ellos. Sin embargo, al comparar cada uno de los gerbos infectados con los aislamientos colombianos de Giardia se observaron variaciones entre los ejemplares presentándose ausencia de quistes en las heces una sola vez en 3 animales y 2 veces en 2 ejemplares.
El inicio de la excreción intermitente de quistes ocurre al día 12 de la infección con los aislamientos de Haití, al día 21 con los de Cuba, Canadá y España, al día 37 con los de Etiopía, mientras que con los de Colombia ocurre más tempranamente, al día 8 posinfección. La duración en el número de días de la ausencia de quistes en heces de los gerbos infectados es de 1 día para los aislamientos de Cuba y Etiopía, de 3 días con los de Haití, de 1 y 3 días con los de Canadá, de 1, 3 y 14 días con los de España y con los colombianos de 1, 3, 4 y 5 días.

La excreción intermitente de quistes es una característica inherente de este protozoario debido a las proteínas involucradas en el proceso y, por lo tanto, relacionadas con la variación antigénica (56). Es posible que debido a la variabilidad genética que presenta el parásito, los patrones de excreción de quistes sean característicos por áreas geográficas y que el proceso de resolución natural de la infección también sea diferente. Así, la infección se resuelve en los gerbos infectados con aislamientos de Giardia circulantes en Etiopía y Haití, Canadá, España y Cuba, aproximadamente, a los días 86, 100 y 114, respectivamente (15) mientras los gerbos infectados con aislamientos colombianos de Giardia resuelven la infección al día 30 (cuarta semana) posinfección.

Llama la atención que existiendo trofozoítos en el intestino delgado no se hubiesen observado quistes del parásito en las heces de los gerbos infectados hasta la resolución de la infección, como se muestra en la figura 1. La ausencia de quistes en materia fecal, existiendo trofozoítos en el intestino delgado en las semanas 1, 2 y 3 posinfección, podría explicarse en términos de la excreción intermitente de quistes que es una característica biológica e inherente del parásito (15) y la ausencia de quistes del parásito en presencia de trofozoítos durante la semana 4 ha sido también informada por otros investigadores $(57,58)$. Este comportamiento podría deberse al desarrollo de inmunoglobulinas séricas $\lg G$, IgM e IgA anti-Giardia y de anticuerpos $\lg _{3}$ o $\lg \mathrm{M}$ anti-parásito en presencia del complemento (59) y a la interacción hospedero-parásito que se encuentra alterada debido a la localización y 
cambios histológicos que los trofozoítos inducen en los animales en la fase final de la resolución de la infección (60). En esta fase de la infección, se conoce que sólo un número reducido de trofozoítos permanece en el duodeno (15) hecho observado en el estudio al cuantificar tan sólo $15.000\left(\log _{10}: 4,2\right)$ trofozoítos de Giardia al día 28 de la infección versus $977.000\left(\log _{10}: 6\right)$, 6'577.778 $\left(\log _{10}: 6,8\right)$ y 2'650.000 $\left(\log _{10}: 6,4\right)$ trofozoítos en los días 7,14 y 21 posinfección, respectivamente. Los trofozoítos se localizan en el duodeno y yeyuno proximal a los días 5,20 y 25 posinfección; en duodeno, yeyuno proximal, yeyuno distal e ileon a los días 10 y 15 y sólo en duodeno al día 30 (15). El ambiente duodenal tiende a ser ácido pero el $\mathrm{pH}$ incrementa gradualmente en el intestino delgado hasta valores entre 7,6 y 8,0 en el yeyuno distal (61). Este pH ligeramente básico en yeyuno distal induce la ionización de ácidos grasos e incrementa su asociación con las sales biliares que promueven el enquistamiento del parásito (62). La presencia de sólo trofozoítos en duodeno y su ausencia en yeyuno distal, sitio en el cual ocurre el enquistamiento (15), podría explicar la ausencia de quistes durante la fase final de la infección en la materia fecal de los gerbos infectados con aislamientos colombianos de Giardia. Complementariamente, durante el proceso de la resolución de la infección por Giardia en el intestino delgado de los gerbos se recupera la proporción vellosidad/criptas intestinales (63) y una vez que las células del epitelio intestinal se encuentran en su estado normal producen óxido nítrico que también inhibe el crecimiento y el enquistamiento de los trofozoítos de Giardia (64).

Los hallazgos de este trabajo permiten concluir que el gerbo constituye un buen modelo animal para la infección experimental con aislamientos colombianos de $G$. duodenalis, que el comportamiento de la infección experimental por los aislamientos colombianos del parásito difiere a lo observado con aislamientos del parásito de otras regiones geográficas y que la infección experimental permite obtener trofozoítos y quistes del parásito en cantidades suficientes con la finalidad de ser utilizados como antígenos para la inmunización de animales y para la obtención de anticuerpos que puedan utilizarse para la detección de antígeno de Giardia en materia fecal.

\section{Agradecimientos}

Los autores expresan sus agradecimientos al Grupo Producción y Desarrollo Tecnológico de la Subdirección de Producción del Instituto Nacional de Salud por el suministro y mantenimiento de los gerbos en el Bioterio Experimental. Al Centro de Salud No.78, José María Carbonel, y al Hospital Infantil Universitario Lorencita Villegas de Santos por las muestras de materia fecal con presencia de Giardia que fueron utilizadas en el ensayo piloto $y$, muy especialmente, a Rafael Guerrero por la selección de pacientes sintomáticos de giardiosis.

\section{Financiación}

Este estudio fue financiado por el Instituto Nacional de Salud.

\section{Conflictos de interés}

Ninguno

\section{Referencias}

1. Adam RD. Biology of Giardia lamblia. Clin Microbiol Rev 2001;14:447-75.

2. Olson ME, Ceri H, Morck DW. Giardia vaccination. Parasitol Today 2000;16:213-7.

3. Flanagan PA. Giardia-diagnosis, clinical course and epidemiology. A review. Epidemiol Infect 1992;109:1-22.

4. Miotti PG, Gilman RH, Santosham M, Ryder RW, Yolken RH. Age-related rate of seropositivity of antibody to Giardia lamblia in four diverse populations. J Clin Microbiol 1986;24:972-5.

5. Galán R, Agualimpia C, Corredor A, Cáceres E. Parasitismo Intestinal - Investigación Nacional de morbilidad. Bogotá, D. E.: Instituto Nacional para Investigaciones Especiales, INPES; 1969.

6. Corredor A, Arciniegas E, Hernández CA, Cáceres $\mathrm{E}$, Castaño de Romero L, Estupiñán $\mathrm{D}$ et al. Parasitismo intestinal. Santa Fe de Bogotá, D. C.: Instituto Nacional de Salud; 2000.

7. Castro de Navarro L, Nicholls S. Deficiencia de hierro, vitamina A y prevalencia de parasitismo intestinal en la población infantil y anemia nutricional en mujeres en edad fértil, Colombia, 1995-96. Santa Fe de Bogotá, D. C.: Instituto Nacional de Salud; 1998.

8. Craun GF. Waterborne giardiasis in the United States 1965-1984. Lancet 1986;2:513-4.

9. Dykes AC, Juranek DD, Lorenz RA, Sinclair S, Jakubowski W, Davies R. Municipal waterborne 
giardiasis: an epidemiological investigation. Beavers implicated as a possible reservoir. Ann Intern Med 1980; 92:165-70

10. Winsland JK, Nimmo S, Butcher PD, Farthing MJ. Prevalence of Giardia in dogs and cats in United Kingdom: survey of an Essex veterinary clinic. Trans R Soc Trop Med Hyg 1989;83:791-2.

11. Roach PD, Olson ME, Whitley G, Wallis PM. Waterborne Giardia cysts and Cryptosporidium oocysts in the Yukon, Canada. Appl Environ Microbiol 1993;59: 67-73.

12. Hill DR. Giardiasis. Issues in diagnosis and management. Infect Dis Clin North Am 1993;7:503-25.

13. Wolfe MS. Giardiasis. Clin Microbiol Rev 1992;5:93100.

14. Xiao L. Giardia infection in farm animals. Parasitol Today 1994;10:436-8.

15. Faubert GM, Belosevic M. Animals models for Giardia duodenalis type organisms. In: Meyer EA, editor. Human parasitic diseases. Volume 3, Giardiasis. Amsterdam: Elsevier Science Publishers Biomedical Division; 1990. p. $77-90$.

16. Hegner RW. Excystation and infection in the rat with Giardia lamblia from man. Am J Hyg 1927;7:782-5.

17. Armaghan V. Biological studies on the Giardia of rats. Am J Hyg 1937;26:236-58.

18. Goritskaya VV, Vrublevskaya LA. Experimental invasion of white rats with Lamblia intestinalis. Med Parazitol Parazit Bol 1966;35:206-8.

19. Sehgal AK, Grewal MS, Chakravarti RN, Broor SL, Deka NC, Chuttani PN. Experimental giardiasis in albino rats. Ind J Med Res 1976;64:1015-8.

20. Woo PTK, Paterson WB. Giardia lamblia in children day care centres in southern Ontario, Canada and susceptibility of animals to G. lamblia. Trans R Soc Trop Med Hyg 1986;80:56-9.

21. Vinayak VK, Sharma GL, Naik SR. Experimental Giardia lamblia infection in Swiss mice, a preliminary report. Ind J Med Res 1979;70:195-8.

22. Hill DR, Guerrant RL, Pearson RD, Hewlett EL. Giardia lamblia infection of suckling mice. J Infect Dis 1983;147:217-21.

23. Boreham PFL, Phillips RE, Shepherd RW. The activity of drugs against Giardia intestinalis in neonatal mice. J Antimicrob Chemoter 1986;18:393-8.

24. Kanwar SS, Walia BNS, Ganguli NK, Mahajan RC. The macrophages as an effector cell in Giardia lamblia infections. Med Microbiol Immunol 1987;176:183-8.

25. Kanwar SS, Ganguli NK, Walia BN, Mahajan RC. Direct an antibody dependent cell mediated cytotoxycity against Giardia lamblia by splenic an intestinal lymphoid cells in mice. Gut 1986;27:73-7.
26. Kanwar SS, Ganguli NK, Walia BNS, Mahajan RC. Changes in mouse splenic lymphocyte sub-copulation during primary and secondary course of Giardia lamblia infection. Ind J Med Res 1985;82:393-7.

27. Samra HK, Garg UR, Ganguli NK, Mahajan RC. Effect of different Giardia lamblia inocula on glucose and amino acids transport in the intestinal brush border membrane vesicles of infected mice. Ann Trop Med Parasitol 1987; 81:367-72.

28. Kirkpatrick CE, Green GA 4th. Susceptibility of domestic cats to infections with Giardia lamblia cysts and trophozoites from human sources. J Clin Microbiol 1985;21:678-80.

29. Hewlett EL, Andrews JS Jr, Ruffier J, Schaefer FW 3rd. Experimental infection of mongrel dogs with Giardia lamblia cysts and cultured trophozoites. J Infect Dis 1982;145:89-93.

30. Healy GR. Giardiasis in perspective: the evidence of animals as a source of human Giardia infections. En: Meyer EA, editor. Human parasitic diseases. Volume 3. Giardiasis. Amsterdam: Elsevier Science Publishers Biomedical Division; 1990. p.305-13.

31. Nash TE, Aggarwal A, Adam RD, Conrad JT, Merritt JW Jr. Antigenic variation in Giardia lamblia. J Immunol 1988;141:636-41.

32. Nash TE, Keister DB. Differences in excretorysecretory products and surface antigens among 19 isolates of Giardia. J Infect Dis 1985;152:1166-71.

33. Smith PD, Gillin FD, Kaushal NA, Nash TE. Antigenic analysis of Giardia lamblia from Afghanistan, Puerto Rico, Ecuador and Oregon. Infect Immun 1982;36:714-9.

34. Nash TE, McCutchan T, Keister D, Dame JB, Conrad JD, Gillin FD. Restriction-endonuclease analysis of DNA from 15 Giardia isolates obtained from humans and animals. J Infect Dis 1985;152:64-73.

35. Bertram MA, Meyer EA, Lile JD, Morse SA. A comparison of isozymes of five axenic Giardia isolates. J Parasitol 1983;69:793-801.

36. Aggarwal A, Merritt JW Jr, Nash TE. Cysteine-rich variant surface proteins of Giardia lamblia. Mol Biochem Parasitol 1989;32:39-47.

37. Aggarwal A, Nash TE. Antigenic variation of Giardia lamblia in vivo. Infect Immun 1988;56:1420-3.

38. Nash TE, Herrington DA, Levine MM, Conrad JT, Merritt JW Jr. Antigenic variation of Giardia lamblia in experimental human infections. J Immunol 1990;144: 4362-9.

39. Melvin DM, Brooke MM. Laboratory procedures for the diagnosis of intestinal parasites. Atlanta: Centers for Disease Control; 1980.

40. Ridley DS, Hawgood BC. The value of formol-ether concentration of faecal cysts and ova. J Clin Pathol 1956;9:74-6. 
41. Sheffield HG, Bjorvatn B. Ultrastructure of the cyst of Giardia lamblia. Am J Trop Med Hyg 1977;26:23-30.

42. Craft JC. Experimental infection with Giardia lamblia in rats. J Infect Dis 1982;145:495-8.

43. Schaefer III FW, Johnson $\mathrm{CH}$, $\mathrm{Hsu} \mathrm{CH}$, Rice EW. Determination of Giardia lamblia cyst infective dose for the mongolian gerbils (Meriones ungüiculatus). Appl Environ Microbiol 1991;57:2408-9.

44. Sauch JF. Purification of Giardia muris cysts by velocity sedimentation. Appl Environ Microbiol 1984;48:454-5.

45. Roberts-Thomson IC, Stevens DP, Mahmoud AAF, Warren KS. Giardiasis in the mouse: an animal model. Gastroenterology 1976;71:57-61.

46. Canadian Council on Animal Care. Guide to the care and use of experimental animals. Vol.1. Ottawa: Canadian Council on Animal Care; 1993.

47. Cedeño D, Lugo L, Muñoz J, Maldonado J. Guía para el uso de los animales de experimentación. Santafé de Bogotá,D. C.: Instituto Nacional de Salud; 1994.

48. Belosevic M, Faubert GM, MacLean JD, Law C, Croll NA. Giardia lamblia infections in Mongolian gerbils: an animal model. J Infect Dis 1983;147:222-6.

49. Hughes HC. Euthanasia of laboratory animals. En: Melby I, editor. Handbook of laboratory animal science. Cleveland: CRC Press; 1976. p.553-9.

50. Beaglehole R, Bonita R, Kjellström T. Epidemiología básica. Washington, D.C.: Organización Mundial de la Salud;1994.

51. Xiao L, Herd RP, McClure KE. Periparturient rise in the excretion of Giardia sp. cysts and Cryptosporidium parvum oocysts as a source of infection for lambs. J Parasitol 1994;80:55-9.

52. Svobodova V, Svobodova M, Konvalinova J. Comparison of the detection of Giardia intestinalis cysts with the presence of specific antibodies in dogs and cats. Vet Med Praha 1995;40:141-6.

53. Khanna R, Kum K, Vinayak VK. Gut-associated immune effector responses in immunocompetent and immuno-compromised mice with Giardia lamblia. FEMS Microbiol Immunol 1990;64:137-46.
54. Byrd LG, Conrad JT, Nash TE. Giardia lamblia infections in adult mice. Infect Immun 1994;62:3583-5.

55. Müller N, Gottstein B. Antigenic variation and the murine immune response to Giardia lamblia. Int J Parasitol 1998;28:1829-39.

56. Udezulu IA, Visvesvara GS, Moss DM, Leitch GJ. Isolation of two Giardia lamblia (WB strain) clones with distinct surface protein and antigenic profiles and differing infectivity and virulence. Infect Immun 1992; 60:2274-80.

57. Stevens DP, Frank DM. Local immunity in murine giardiasis: Is milk protective at the expense of maternal gut? Trans Assoc Am Phys 1978;91:268-72.

58. Iwanczuk I. Studies on the distribution of Lamblia muris in the alimentary tract of white mice. Acta Parasitol Polon 1968;15:367-73.

59. Heyworth MF. Relative susceptibility of Giardia muris trophozoites to killing by mouse antibodies of different isotypes. J Parasitol 1992;78:73-6.

60. Olveda RK, Andrews JS Jr., Hewlett EL. Murine giardiasis: localization of trophozoites and small bowel histopathology during the course of infection. Am J Trop Med Hyg 1982;31:60-6.

61. Fordtran JS, Locklear TW. Ionic constituents and osmolality of gastric and small-intestinal fluids alter eating. Am J Digest Dis 1966;11:503-21.

62. Schupp DG, Reiner DS, Gillin FD, Erlandsen SL. In vitro encystation of Giardia. In: Meyer EA, editor. Human parasitic diseases. Volume 3, Giardiasis. Amsterdam: Elsevier Science Publishers Biomedical Division; 1990. p.137-54.

63. Buret A, Gall DG, Nation PN, Olson ME. Intestinal protozoa and ephitelial cell kinetics, structure and function. Parasitol Today 1990;6:375-80.

64. Eckmann L, Laurent F, Langford TD, Hetsko ML, Smith JR, Kagnoff MF et al. Nitric oxide production by human intestinal epithelial cells and competition for arginine as potential determinants of host defense against the lumen-dwelling pathogen Giardia lamblia. J Immunol 2000;164:1478-87. 